\title{
Addressing cancer prevention and control in Armenia: tobacco control and mHealth as key strategies
}

\author{
Carla J. Berg ${ }^{\text {* }^{*} \text {, Arusyak Harutyunyan², Nino Paichadze }}$, Adnan A. Hyder ${ }^{3}$ and Varduhi Petrosyan²
}

\begin{abstract}
This paper focuses on the particular challenges in cancer prevention and control (CPC) in low- and middle-income countries (LMICS). In particular, this paper extrapolates challenges and opportunities in Armenia, which has the 2nd highest rate of cancer-related deaths in the world, the 11th highest smoking prevalence among men globally, and an evolving health system infrastructure for non-communicable disease (NCD) prevention and control, including CPC. Despite significant progress in enhancing research capacity in Armenia over the past decade, additional efforts are needed, particularly in CPC-related research. Key opportunities are to advance tobacco control and utilization of mHealth. Public health training programs remain insufficient in the area of $C P C$, and in-country research expertise regarding CPC and related areas (e.g., tobacco control, mHealth, policy) is limited, particularly given the need to address the diverse and complex determinants of onset, prevention, and management of cancer. Moreover, critical gaps in research dissemination and knowledge translation from evidence to policy and practice continue to exist. Thus, public health infrastructure must be enhanced, in-country CPC leaders across various relevant disciplines must be further developed and supported, and medical and public health training must more fully integrate CPC and research dissemination and translation to inform policy and practice.
\end{abstract}

Keywords: Cancer prevention, Cancer control, Tobacco control, Policy, mHealth

\section{Overview}

This paper focuses on challenges in cancer prevention and control (CPC) in low- and middle-income countries (LMICs), particularly in Armenia, which has the 2nd highest rate of cancer-related deaths in the world, the 11th highest smoking prevalence among men globally, and evolving health system infrastructure for noncommunicable disease $(\mathrm{NCD})$ prevention and control, including CPC [1-3].

\footnotetext{
* Correspondence: carlaberg@gwu.edu

${ }^{1}$ Department of Prevention and Community Health, Milken Institute School of Public Health, George Washington Cancer Center, George Washington University, Washington, DC, USA

Full list of author information is available at the end of the article
}

\section{Global impact of cancer}

Cancer is the second leading cause of death globally, causing $\sim 1$ in 6 deaths [4]. The most common cancers are lung, breast, colorectal, prostate, skin (non-melanoma), and stomach, with several of these also causing the most cancer-related deaths (e.g., lung, colorectal, stomach, breast) [4]. Based on population growth and aging, the global cancer burden will grow to $29.4 \mathrm{M}$ cases annually in 2040 [4].

LMICs account for $\sim 70 \%$ of cancer-related deaths [4] and, by 2030 , will account for $75 \%$ of new cancer cases and deaths [4]. Although several countries have achieved significant cancer burden reductions, disparities in progress exist [4]. While incidence of preventable malignancies (e.g., lung) has decreased in high-income countries (HICs) but has not changed or increased in LMICs [4].

\section{$\triangle B M C$}

(c) The Author(s). 2021 Open Access This article is licensed under a Creative Commons Attribution 4.0 International License, which permits use, sharing, adaptation, distribution and reproduction in any medium or format, as long as you give appropriate credit to the original author(s) and the source, provide a link to the Creative Commons licence, and indicate if changes were made. The images or other third party material in this article are included in the article's Creative Commons licence, unless indicated otherwise in a credit line to the material. If material is not included in the article's Creative Commons licence and your intended use is not permitted by statutory regulation or exceeds the permitted use, you will need to obtain permission directly from the copyright holder. To view a copy of this licence, visit http://creativecommons.org/licenses/by/4.0/ The Creative Commons Public Domain Dedication waiver (http://creativecommons.org/publicdomain/zero/1.0/) applies to the data made available in this article, unless otherwise stated in a credit line to the data. 
$\mathrm{CPC}$ is a critical component in reducing cancer burden and disparities. Five behavioral risks (tobacco use, alcohol use, overweight/obesity, low fruit/vegetable intake, low physical activity) contribute to $\sim 1 / 3$ of cancer deaths, $30-50 \%$ of which are preventable by avoiding risk factors and implementing evidence-based prevention strategies [4]. Additionally, early detection and treatment can reduce cancer mortality [4]. However, late-stage presentation and inaccessible diagnosis and treatment are prominent in LMICs [4].

\section{Global impact of tobacco}

The tobacco epidemic is among the biggest global health threats, with $>7 \mathrm{M}$ tobacco-related deaths per year [5] with estimated increases to $>8 \mathrm{M}$ per year by 2030 [5]. Tobacco use is among the most important cancer risk factors - responsible for $\sim 22 \%$ of cancer deaths (and other chronic diseases, e.g., cardiovascular diseases) [5]. Nonsmokers are also impacted via secondhand smoke exposure (SHSe); 1.8B nonsmokers, including $40 \%$ of children and $\sim 34 \%$ of adult nonsmokers experience SHSe, estimated to kill $>600,000$ annually [6]. Unfortunately, only $7 \%$ of the world lives in places with comprehensive smoke-free laws [6].

Tobacco-related morbidity and mortality is increasingly burdening LMICs [5]; $80 \%$ of the $933 \mathrm{M}$ current daily smokers [5] live in LMICs [5], half of whom will die prematurely due to smoking [5]. The disproportionate impact of tobacco use is also reflected in the impact of SHSe [6].

\section{Global action to address CPC \& tobacco}

In 2017, the World Health Assembly passed the Cancer Prevention and Control through an Integrated Approach to catalyze acheiving specific targets in the Global Action Plan and 2030 UN Agenda for Sustainable Development (to reduce premature cancer mortality). Key priorities include surveillance, CPC research and translation, identifying cost-effective priority CPC strategies, and developing standards/tools to guide interventions and health systems improvements to address cancer across the cancer continuum.

Additionally, for over a decade, the World Health Organization (WHO) Framework Convention on Tobacco Control (FCTC) has promoted adoption of comprehensive evidence-based policies (e.g., taxation, smoke-free air) to counter the tobacco epidemic; 181 countries have ratified the FCTC (covering 90\% of the world's population), most of which are LMICs [7].

\section{mHealth interventions in LMICs}

Identifying solutions to address cancer burden in LMICs with wide reach, strong potential for scale-up, and the ability to strengthen existing health systems is critical.
mHealth (i.e., mobile/wireless devices to improve health) has shown utility in increasing healthcare access, quality, effectiveness, and cost-effectiveness [8]. The potential utility and impact of mHealth in LMICs is particularly great, given the popularity and availability of mobile devices across demographics and contexts and given that access to mobile phones is often greater than access to regular healthcare in many LMICs [8].

However, mHealth technology adoption is higher in HICs versus LMICs [8], perhaps due to better understanding, skills, and resources to build and implement mHealth, not the least of which are human capacities/understanding [8]. In LMICs, most health systems are overstrained and face ongoing challenges to make complex decisions about competing priorities [8]. Thus, promoting mHealth as one relevant, potentially high-impact solution to healthcare challenges is critical in addressing cancer and general NCD burden in LMICs [8]. This priority aligns with several current initiatives to advance the mHealth evidence-base and its use in other sectors of health, particularly in LMICs [8].

\section{Health \& risk factors in Armenia}

Armenia is in particular need of focused efforts to reduce its cancer burden. Despite a life expectancy of 76 years (72 in men vs. 79 in women; World Life Expectancy ranking of 87) [1-3], Armenia faces particular NCD-related challenges. Figure 1 [2] shows the top causes of death and premature death and the top risk factors for disability and death in Armenia in 2007-2017. Cancer is the second most prominent cause of death and premature death in Armenia [2]. Moreover, Armenia has the 2nd highest rate of cancer-related deaths in the world (198 per $100 \mathrm{~K}$ people; behind Mongolia) [2, 3]. While some of its neighbors rank closely behind (e.g., Hungary 3rd, Slovakia 5th, Russia 10th, etc.), its closest neighbors rank far better (Turkey 41st, Georgia 82nd, Azerbaijan 93rd, Iran 120th) [1-3]. Furthermore, Armenia has the 8th highest lung cancer death rate and also fairs poorly for other cancers (e.g., 3rd for pancreas, 7th bladder, 19th breast), despite Armenia ranking 97th in cancer prevalence worldwide [1-3].

Among the top risk factors in Armenia is tobacco use - which is associated with nearly all top causes of death and premature death, including cancer [2]. Overall, $28 \%$ of Armenian adults currently smoke (almost all smoke daily) [1]; noteworthy is that (while $2 \%$ of women smoke) $52 \%$ of men smoke - the 11 th highest smoking prevalence among men globally. Not surprisingly, SHSe in Armenia is high (e.g., $>50 \%$ report past-month SHSe at home; $\sim 1 / 3$ at work) [9], underscoring broad impact of tobacco in Armenia. 


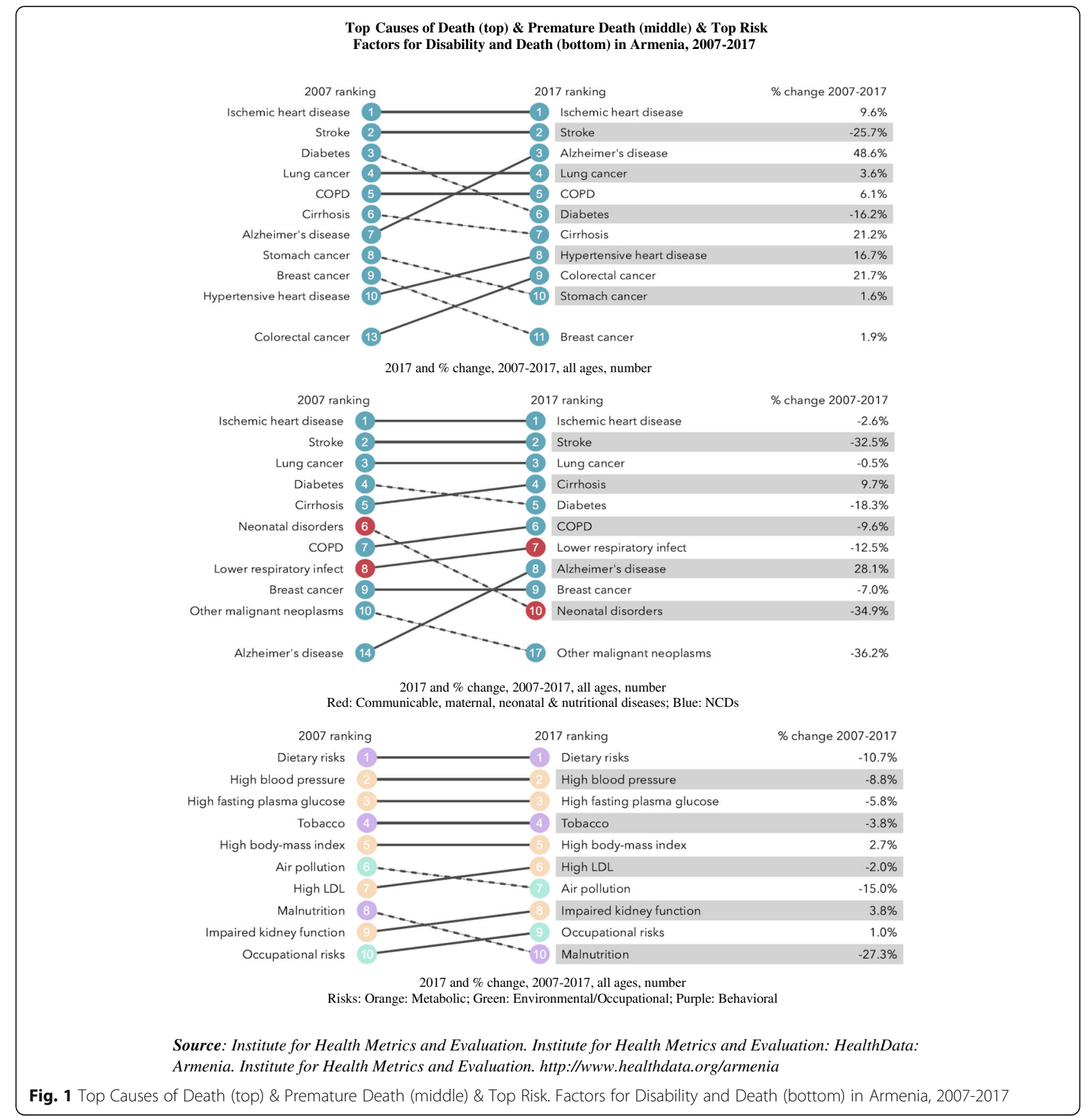

Furthermore, Armenia's health system is evolving with regard to infrastructure for NCD prevention and control, including $\mathrm{CPC}$, making enhancements to such infrastructure (such as those possible via mHealth) among the highest public health and healthcare priorities in Armenia [2].

\section{Addressing cancer and tobacco in Armenia}

Armenia has identified gaps in implementing WHOrecommended cost-effective NCD preventive and clinical interventions. Several policy and legislative frameworks are in place for NCDs, including the 1) National Strategic Program, with focus on 3 diseases with high mortality rates (cardiovascular disease, cancer, diabetes); 2) Strategic Program for the Prevention and Control of NCDs; 3) Strategy for Promoting Healthy Lifestyles; and 4) Tobacco Control Strategy. Two priorities identified across these frameworks are 1) tobacco control and 2) technological advances to enhance healthcare access, quality, and cost-effectiveness. 


\section{Tobacco control}

Despite Armenia ratifying of the FCTC in 2004, tobacco control has lagged, and tobacco use and related diseases have shown little decline. However, in February 2020, Parliament passed new tobacco control legislation, which was signed into law in March 2020. This law harmonizes Armenian tobacco control with the WHO FCTC and takes progressive action to extend smoke-free bans apply to all tobacco products and to all public places and toward industry marketing (i.e., tobacco display/ad bans, plain packaging). This provides a pivotal time for 1) catalyzing legislation impact to reduce tobacco use, morbidity, and mortality and 2) advancing the global evidence-base for tobacco control by researching the implementation and impact of the legislation.

\section{mHealth in Armenia}

Mobile phone and internet access and utilization have advanced considerably throughout the country in both rural and urban settings. In the context of this broad coverage, some advances have been made. For example, in 2014, an initiative to institutionalize patient-centered tuberculosis treatment and improve treatment adherence was launched, led by the Turpanjian School of Public Health at American University of Armenia, the Ministry of Health of the Republic of Armenia, and the National Center of Pulmonology. This multifaceted program is now implemented nationwide and includes text message reminders to prompt patients to take their medication and track treatment adherence. In addition, Armenia's Strategy for the Development of Science focuses on developing its technology and healthcare IT infrastructures, making this a pivotal time to bolster mHealth as potentially high-impact asset that can be leveraged to reduce cancer risk behaviors, reduce health system costs, improve access to healthcare services, and/or improve quality and effectiveness of healthcare services. However, Armenia has yet to fully take advantage of mHealth or telemedicine approaches for $\mathrm{CPC}$, underscoring the need for training programs that promote mHealth in the context of NCD treatment and research.

\section{Need for research training in CPC risk factors}

Despite significant progress in enhancing research capacity in Armenia over the past decade, additional efforts are needed, particularly in CPC-related research. Public health training programs remain underdeveloped in the area of $\mathrm{CPC}$, and in-country research expertise regarding $\mathrm{CPC}$ and related areas (e.g., mHealth, policy) is relatively limited, particularly given the need to address the diverse and complex determinants of cancer onset, prevention, and management. Moreover, critical gaps in research dissemination and knowledge translation from evidence to policy and practice continue to exist. Thus, there is a need to continue to enhance public health infrastructure, in-country $\mathrm{CPC}$ leaders across various relevant disciplines must be further developed and supported, and medical and public health training must more fully integrate $\mathrm{CPC}$ and research dissemination and translation to inform policy and practice and ultimately reduce Armenia's cancer burden [10].

\section{Authors' contributions \\ CJB led the writing of the manuscript. AH, NP, AAH, and VP contributed to the content and reviewed drafts. All authors reviewed and approved the final manuscript for submission.}

\section{Funding}

This work was supported by the Fogarty International Center/NIH (1R01TW010664-01; MPIs: Berg, Kegler). Dr. Berg is also supported by other $\mathrm{NCl}$ funding (R01CA179422-01; Pl: Berg; R01CA215155-01A1; PI: Berg; R01CA239178-01A1; MPIs: Berg, Levine) and the NIEHS/Fogarty (D43ES030927-01; MPIs: Berg, Marsit, Sturua).

\section{Availability of data and materials}

N/A.

\section{Ethics approval and consent to participate} N/A.

\section{Consent for publication}

All authors have approved this manuscript for submission. Human subjects $\mathrm{N} / \mathrm{A}$.

\section{Competing interests}

The authors declare no conflicts of interest.

\section{Author details}

${ }^{1}$ Department of Prevention and Community Health, Milken Institute School of Public Health, George Washington Cancer Center, George Washington University, Washington, DC, USA. ${ }^{2} T$ urpanjian School of Public Health, American University of Armenia, Yerevan, Armenia. ${ }^{3}$ Center on Commercial Determinants of Health and Department of Global Health, Milken Institute School of Public Health, Washington, DC, USA.

Received: 31 October 2020 Accepted: 1 December 2020

Published online: 06 January 2021

\section{References}

1. Farrington J, Kontsevaya A, Fediaev D, et al. Prevention and control of noncommunicable diseases in Armenia: the case for investment. World Health Organization. https://iogt.org/wp-content/uploads/2019/05/WHONCD-case-for-investment_Armenia.pdf. Published 2019. Accessed.

2. Institute for Health Metrics and Evaluation. Institute for Health Metrics and Evaluation: HealthData: Armenia. Institute for Health Metrics and Evaluation. http://www.healthdata.org/armenia. Published 2019. Accessed.

3. World Health Rankings. World health rankings, 2018: cancer death rate by country; 2019.

4. Jemal A, Torre L, Soerjomataram I, Bray F. The Cancer atlas. 3rd ed. Atlanta: American Cancer Society; 2020

5. World Health Organization. WHO report on the global tobacco epidemic, 2015. Geneva: World Health Organization; 2015.

6. World Health Organization. Worldwide burden of disease from exposure to second-hand smoke. World Health Organization. http://www.who.int/ quantifying_ehimpacts/publications/shsarticle2010/en/. Published 2018. Accessed.

7. World Health Organization. Parties to the WHO Framework Convention on Tobacco Control. World Health Organization. http://www.who.int/fctc/ signatories_parties/en/. Published 2016. Accessed.

8. World Health Organization. 2019 WHO guideline: recommendations on digital interventions for health system strengthening. Geneva: World Health Organization; 2019. 
9. Andreasyan D, Bazarchyan A, Saghatelyan A, Sargsyan S, Torosyan A, Karapetyan H. NCD STEPS national survey. Yerevan: National Institute of Health after academician S. Avdalbekyan, Ministry of Health, Republic of Armenia; 2018.

10. Labrique A, Vasudevan L, Mehl G, Rosskam E, Hyder AA. Digital health and health Systems of the Future. Glob Health. 2018;6(Supplement 1):S1-4.

\section{Publisher's Note}

Springer Nature remains neutral with regard to jurisdictional claims in published maps and institutional affiliations.

- fast, convenient online submission

- thorough peer review by experienced researchers in your field

- rapid publication on acceptance

- support for research data, including large and complex data types

- gold Open Access which fosters wider collaboration and increased citations

- maximum visibility for your research: over $100 \mathrm{M}$ website views per year

At $\mathrm{BMC}$, research is always in progress. 